\title{
Analysis of earthquake parameters to generate hazard maps by integrating AHP and GIS for Küçükçekmece region
}

\author{
T. Erden and H. Karaman \\ Department of Geomatics Engineering, Faculty of Civil Engineering, Istanbul Technical University, 34469 Istanbul, Turkey \\ Correspondence to: H. Karaman (karamanhi@itu.edu.tr)
}

Received: 27 October 2011 - Revised: 28 December 2011 - Accepted: 3 January 2012 - Published: 29 February 2012

\begin{abstract}
Definition of an earthquake includes parameters with respect to region of interest. Each of those parameters has different weights on the earthquake ground motion and effect. This study examines the weight of common parameters that have an influence on the effects of earthquakes. The Analytic Hierarchy Process (AHP) is used for factor weighting of each parameter and Geographic Information Systems (GIS) are used for simulating the results of the AHP on a spatial environment. In this study, it is aimed to generate a hierarchical structure of the model for the simulation of an earthquake hazard map (EHM). The parameters of the EHM, which are selected by the criterion of non-correlated factors, are: topography, distance to epicenter, soil classification, liquefaction, and fault/focal mechanism. As a result of the study, weights of the parameters that affect the earthquake ground motion at the study area are determined and compared with a selected attenuation relation map.
\end{abstract}

\section{Introduction}

Systems in emergency management are being used for the important purposes of response planning and formulating risk reduction policies. The ingredients of seismic loss assessment include hazard (exposure), vulnerability or fragility (sensitivity), inventory (value) and integrated visualization (losses) (Karaman et al., 2008a). Turkey is one of the most seismically active countries in the world. According to Parsons et al. (2000) and Parsons (2004), the probability of a $M \geq 7$ earthquake rupturing beneath the Sea of Marmara at the south of Istanbul is approximately $35-70 \%$ in the next $30 \mathrm{yr}$. The necessity of comprehensive plans for seismic mitigation, response and recovery tasks after catastrophic events has encouraged researchers to develop scientifically advanced tools to conduct loss assessment analyses (Karaman et al., 2008b). This study mainly focuses on the hazard section of the loss assessment cycle.
Hazard, when defining an earthquake, is described as an input ground motion parameter or a spectral response value. Integrated visualization is an essential framework in which to use the assessment parameters hazard, fragility and inventory in order to evaluate physical and economical impact, given the loss functions that translate damage into loss of value (Karaman et al., 2008a). The main ingredients comprising the hazard parameter are fault/focal mechanism, earthquake scenario, attenuation models, soil classification, liquefaction potential, and topography of the region. All of the above have influence on the impact of the earthquake on the study region. The methods that were used to derive the data and the approaches that were followed could affect the results of the hazard element. For example, use of an attenuation model with the same earthquake scenario and with the same focal mechanism, can give different results if the soil classification or liquefaction or topographic effects are given different weights or vice versa. Even a change to the smallest weighted ingredient gives a different result for the hazard parameter (Karaman, 2009). To simulate the effect of an earthquake at a specific region, a proper attenuation relation or a group of weighted attenuation relations are used. "An attenuation relation, or ground motion model as seismologists prefer to call it, is a mathematical based expression that relates a specific strong motion parameter of ground shaking to one or more seismological parameters of an earthquake. These seismological parameters quantitatively characterize the earthquake source, the wave propagation path between the source and the site, and the soil and geological profile beneath the site" (Lee et al., 2002). The most common form of attenuation relation can be formed as;

$\ln Y=c 1+c 2 M-c 3 \ln R-c 4 r+c 5 F+c 6 S+\varepsilon$

"where (ln) represents the natural logarithm, $Y$ is the strong motion parameter of interest, $M$ is earthquake magnitude, $r$ is a measure of source-to-site distance, $F$ is a parameter characterizing the type of faulting, $S$ is a parameter characterizing 
the type of local site conditions, $\varepsilon$ is a random error term with zero mean and standard deviation equal to the standard error of estimate of $\ln Y\left(\sigma_{\ln Y}\right)$, and $R$ is a distance term" (Lee et al., 2002). The mathematical relation and the parameters of $c 1$ to $c 6$ have their roots in the earthquake seismology (Lay and Wallace, 1995).

"A considerable number of attenuation laws, predicting strong motions of the ground in terms of magnitude, distance, site geology, and in some cases of other additional factors, using a variety of models and data sets, have been derived for different parts of the world and reviews of these laws are available" (Ambraseys and Bommer, 1991). There are also a number of reviews of attenuation studies available in the literature which provide a good summary of the methods used, the results obtained and the problems associated with such relations (Douglas, 2004). Approximately, there are over 300 attenuation relations that exist worldwide. Some of them can be used for several geographic regions and some of them can only be used for the region that it was created for. There are also several studies to evaluate the applicability of the attenuation relations for the different regions. "The applicability of the attenuation relations on the question of whether the models used for the prediction of ground motions in a given region need to be derived from strong-motion data recorded in that region, or whether good-quality data from other tectonically compatible regions can be used to constrain models for physical processes for which recorded data at the region are insufficient. A corollary question is whether ground motions vary on a regional scale" (Stafford et al., 2008). There is still no agreement on the use of the attenuation relations on different regions, and it is still in discussion which attenuation relation predicts the best results for a possible earthquake. Another discussion is on the type of the strong motion parameter $Y$. Some scientists prefer to use peak ground acceleration (PGA), while others prefer to use spectral displacement $(\mathrm{Sd})$. To estimate the damage to buildings, some researchers choose spectral acceleration ( $\mathrm{Sa}$ ) for a certain period; and to estimate the damage to the utilities, peak ground velocity (PGV) is broadly used. Although most of the strong motion parameters can be derived or integrated from each other, the mathematical derivation and/or integration increases the amount of the uncertainty. Since the whole process is based on estimations, increases to uncertainty levels must be avoided. As the complexity of the attenuation relations increases, the mathematical calculation time also increases. It is also important to achieve high resolution hazard maps to decrease the uncertainty in the whole earthquake loss-assessment process. Thus, both the number of the pixels for the hazard map and the number of the calculations increases.

It is also important in the field of emergency management to determine the results as rapidly as possible and as accurately as possible. Therefore, minimization of the conflicts and the uncertainties in determination of the hazard maps is an important need for the emergency management procedure.
Nowadays, multi-criteria decision making and analytic hierarchy process are being used widely in industrial and operational research areas. These procedures are selected in the field of emergency management to reduce the time to determine the hazard maps.

Spatial multi-criteria decision (MCD) problems typically involve a set of geographically-defined alternatives (events) from which a choice of one or more alternatives is made with respect to a given set of evaluation criteria (Jankowski, 1995; Malczewski, 1999). Spatial multi criteria (SMC) analysis is vastly different from conventional Multi-Criteria Decision Making (MCDM) techniques due to inclusion of an explicit geographic component. In contrast to conventional MCDM analysis, SMC analysis requires information on criterion values and the geographical locations of alternatives in addition to the decision makers' preferences with respect to a set of evaluation criteria. This means analysis results depend not only on the geographical distribution of attributes, but also on the value judgments involved in the decision making process. Therefore, two considerations are of paramount importance for SMC decision analysis. The first consideration is the GIS component (e.g., data acquisition, storage, retrieval, manipulation, and analysis capability); and the second one is the MCDM analysis component (e.g., aggregation of spatial data and decision makers' preferences into discrete decision alternatives) (Carver, 1991; Jankowski, 1995).

Many spatial decision making problems, such as site selection or land use allocation, require the decision maker to consider the impacts of choice alternatives along multiple dimensions in order to choose the best alternative. An example that clearly defines the process with an application of site selection can be found from Erden and Coskun (2010).

This study based on the Analytic Hierarchy Process (AHP), which is one of the most commonly used MCDM tools. AHP is a method that allows the consideration of both objective and subjective factors in ranking alternatives. Since its introduction in the mid 1970s, AHP has been applied in a wide variety of practical including economics, planning, energy policy, health, conflict resolution, site selection, project selection, and budget allocation. AHP assists the decision making process by allowing decision-makers to organize the criteria and alternative solutions of a decision problem in a hierarchical decision model.

\section{AHP theory and use in emergency management}

The aim of the emergency management process is to avoid the disasters before they occur. However, it is not always possible to avoid disasters. That is when the emergency management cycle intervenes. Emergency management is there to mitigate the possible losses, to be prepared for the expected disasters, to be able to respond in time to the right place, and to recover the losses as soon and as well as possible. 
In all four phases of the emergency management cycle, results of the loss assessment are used. To be prepared and mitigate the losses, the hazard maps are used to find out the risky areas for relevant structures and assets and to plan when removal or retrofit of those assets are done. To be able to respond to the right place, in time and with correct equipment, the hazard maps are used to find out where are the most hazardous areas, what will be the amount of losses there, and what will be the type of damage to respond to and with which relevant equipment. Finally, to be able to recover the losses with minimum cost and maximum help, the amount of the damage should be known and the required process should be ready. As mentioned above, the AHP helped us to reduce the time to create comparable earthquake hazard maps.

AHP was developed by Saaty (1980) and has been an effective tool for decision makers and researchers since its invention. Among the other multiple criteria decision-making tools, it is one of the most widely used (Vaidya and Kumar, 2006).

In AHP, the decision problem is first decomposed into a hierarchy of more easily comprehended sub-problems that can be analyzed independently. The elements of the hierarchy can relate to any aspect of the decision problem. Once the hierarchy is built, the decision makers systematically evaluate its various elements by comparing them to one another two at a time. In AHP, comparing only two elements at a given time greatly reduces the conceptual complexity of an analysis. Given a pairwise comparison, the analysis involves three steps. The first step is developing a comparison matrix at each level of the hierarchy, starting from second level to the last level. The second step consists of computing the relative weights for each element of the hierarchy, and the third step originates by estimating the consistency ratio to check the consistency of the judgments (Saaty, 1980).

\section{Methodology and data analysis}

The choice of MCDM techniques and an approach to integration with GIS depends on the type of data model used in GIS. In a raster-based GIS each individual cell is regarded as a choice alternative and, hence, it is a candidate for evaluation. The number of cells in the majority of raster maps makes it impractical to use computationally intensive MCDM techniques based on pairwise comparisons of all alternatives (i.e., concordance analysis). In this case, one can advocate weighted summation as the useful and practical MCDM technique for raster GIS. The multiple criteria evaluation, with weighted summation integrated into a raster GIS, becomes then a two-step procedure where a suitability map is developed first, followed by the rank ordering of cells (Jankowski, 1995).

This study is based on GIS structure. GIS uses digital maps to analyze the data spatially. Maps are drawn according to the standards to visualize the related data. The visualization of the spatial data is based on cartography science concerned with the projection, usage and features of graphic signs, drawing techniques, plotting and usage methods of maps. In cartographic representation it is suggested that tone scale should not include more than seven tone values (Schoppmeyer, 1978). Therefore, the parameters are visualized by using GIS and maps are classified into 4 classes of representation in this study. After determining criteria value ranges, the ranking of the class values from 1 to 4 is assigned with respect to scientific codes and assumptions.

The data classification methods in GIS can be named as: manual, equal interval, quantile, natural breaks (jenks), and standard deviation. While the manual classification divides the total range of features from maximum to minimum into user-specified ranges, the equal interval classification divides the total range of features from maximum to minimum into equal sub-ranges. Both of these methods create an easy to understand legend and work best with continuously distributed data (ESRI, 2011). The data in this study classified both using manual and equal interval methods. Various datasets derived from various disciplines need to be classified according to the related code or regulations. Criteria value ranges and the ranking of the corresponding class values are represented in Table 1.

To determine the criteria priorities/weights of the data, a questionnaire is prepared for forming the pairwise comparison matrix according to Saaty's pairwise comparison scale. The questionnaire is conducted to determine the expert opinions of academicians by different disciplines.

The respondents were ten academicians including civil, geomatics, geology, and geophysics engineers. Table 2 represents one of the respondents' preference matrices. AHP also helps to incorporate a group consensus. This procedure consists of a questionnaire for comparison of each element and geometric mean to arrive at a final solution (Golden et al., 1989). Geometric means of all paired comparison judgments are calculated for each question in order to reveal the aggregated group judgments in Table 2.

As an important indicator of AHP process, the $\lambda_{\max }$ value is used as a reference index by calculating the consistency ratio $(\mathrm{CR})$ of the estimated vector. In order to calculate the $\mathrm{CR}$, the consistency index $(\mathrm{CI})$ for each matrix of order $\mathrm{n}$ can be computed by the following equation (Saaty, 1980):

$\mathrm{CI}=\frac{\lambda_{\max }-n}{n-1}$

Using Eq. (2), the CR can be calculated by the expression given below:

$\mathrm{CR}=\frac{\mathrm{CI}}{\mathrm{RI}}$.

In Eq. (3), the random consistency index is obtained from a randomly generated pairwise comparison matrix. The values of RI from matrices of order 1 to 10 can be found from 
Table 1. Criteria value ranges and their assigned class values with the calculated criteria priority/weight.

\begin{tabular}{lccccr}
\hline Criteria & \multicolumn{4}{c}{ Class Values } & Weights/Priorities \\
\cline { 2 - 5 } & 1 & 2 & 3 & 4 & \\
\hline FT (field topography) (degrees) & $0-10$ & $10-15$ & $15-30$ & $30<$ & $0.06(\% 6)$ \\
DS (source to site distance) (km) & $22.21-19.80$ & $19.80-17.38$ & $17.38-14.97$ & $14.97-12.55$ & $0.38(\% 38)$ \\
SC (soil classification) (m s ${ }^{-1}$ ) & $800-760$ & $760-360$ & $360-180$ & $180-50$ & $0.24(\% 24)$ \\
LP (liquefaction potential) & $104-103$ & $103-102$ & $102-101$ & 101 & $0.22(\% 22)$ \\
FM (fault/focal mechanism) & $0.45-0.53$ & $0.53-0.61$ & $0.61-0.68$ & $0.68-0.76$ & $0.10(\% 10)$ \\
\hline
\end{tabular}

Saaty's (1980) work. There is a control for the pairwise comparisons at each level of hierarchy. If $\mathrm{CR}<0.10$, then pairwise comparisons are acceptable. If $\mathrm{CR} \geq 0.10$, the values of ratio are indicative of inconsistent judgments. In such cases, one should reconsider and revise the original pairwise comparison matrix A (Saaty, 1980).

By using the $\lambda \max , \mathrm{CI}$ and $\mathrm{CR}$ values for a group decision making, the weight vector for the five criteria in the last column of Table 1 are computed.

\section{GIS data and model building}

The five criteria of the study are also basic components of attenuation modeling process and can also be mapped. In this study it is aimed to acquire the maps of all five criteria by classifying them according to related codes. Classification is done to help the decision makers understand the situation and distribute the components rapidly by just looking at the map. The whole process for GIS data and analyses are carried out by using the ArcGIS 10 software Model Builder tool. In this way an automated GIS system is also constituted for these kinds of studies.

\subsection{Field topography}

The effect of topography is an important factor in earthquake hazards. Although there is still no agreement on the modeling of the affects of the topography, Eurocode 8 defined an assumption to determine and classify the effects by means of slope angle. Field topography has an amplification affect with respect to height and slope angle; further information can be found from the Eurocode 8-Part 5 (CEN, 2004). Amplification factors of topography are derived from the digital elevation model (DEM) of the study region. The DEM data consist of slope angles of the related cells and the data classified to 4 classes with respect to ranges in Table 1 .

\subsection{Source to site distance}

Effect of the earthquake attenuates as the distance from the epicenter of the earthquake increases. The reverse effect of the distance from source, which is the epicenter of the earthquake, to sites of various locations at the region of interest, is modeled by classifying the distance into four classes.

Model creation for the determination of the source to site distance required a raster map of the region to be converted to square gridded polygon feature, which will be converted to vector data consisting of points to calculate the horizontal distance between the point location of the epicenter and each feature of the study region. Then, every point is to be spatially joined to the polygon conjugate at the study region and the resulting polygon feature is to be converted to raster map with the distance values. The last step is for classification of the resulting raster map to four classes.

\subsection{Soil classification}

Based on the detailed soil maps of the study region, the soil classification is determined with respect to National Earthquake Hazard Reduction Program's (NEHRP) 1997 regulations (National Earthquake Hazards Reduction Program (US) et al., 2004). The shear velocity values at $30 \mathrm{~m}$ are used in classification. The related ranges of the data for each class can be found in Table 1 .

\subsection{Liquefaction potential}

The liquefaction potential index (LPI) is useful for spatial analysis of liquefaction hazard because it allows the two-dimensional representation of a three-dimensional phenomenon (i.e., FS vs. depth), which is ideal for mapping (Luna and Frost, 1998). LPI also correlates well with liquefaction effects (Toprak and Holzer, 2003). The input for the study is a raster dataset that contains the probability from no liquefaction risk (DL) to major liquefaction risk (AL). The dataset itself has four classes but the situation classification is also important. While DL creates no risk (its class value is 1 ), the AL has the potential of major risk and is classed as 4 . The details of the classification ranges are given in Table 1 .

\subsection{Fault/focal mechanism}

The hazard level at a site is obtained by assessing the effects of a given seismic source zone, characterized by its geometry and its recurrence relationship, through an attenuation law 
Table 2. Preference (pairwise comparison) matrix for one respondent (a) and for group judgement (b).

(a)

\begin{tabular}{lrrrrr}
\hline Criteria & FT & DS & SC & LP & FM \\
\hline FT & 1 & 0.2 & 0.2 & 0.2 & 0.5 \\
DS & 5 & 1 & 1 & 3 & 4 \\
SC & 5 & 1 & 1 & 3 & 3 \\
LP & 5 & 0.33 & 0.33 & 1 & 3 \\
FM & 2 & 0.25 & 0.33 & 0.33 & 1 \\
\hline$\lambda \max =5.2$ & \multicolumn{1}{c}{$\mathrm{CI}=0.05$} & \multicolumn{2}{c}{$\mathrm{CR}=0.04<0.1$}
\end{tabular}

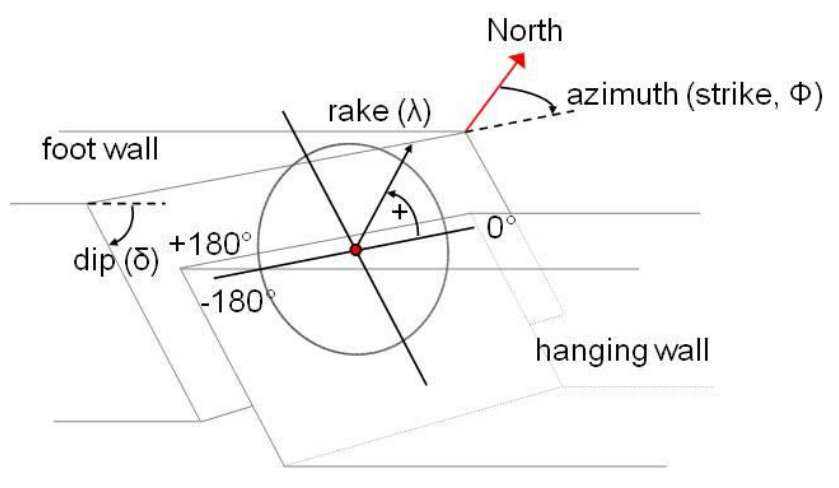

Fig. 1. Visualization of fault and focal mechanism (Elnashai et al., 2008).

(Ambraseys, 1995; Boore, 1997). When an earthquake occurs only a part of a fault is involved in the rupture. The point where an earthquake rupture initiates is called the hypocenter or focus, and if hypocenter is projected to Earth's surface, the intersected point is called as the epicenter.

The focal geometry of earthquakes can vary depending on the orientation of the foot wall and hanging wall or so-called double-couple representing the source. Three angles are necessary to describe the focal mechanism of an earthquake: strike or azimuth, dip, and rake or slip (Stein and Wysession, 2003). The visualization of the fault and focal mechanism can be seen in Fig. 1. Based on these angle combinations, the type of fault can be determined. According to fault type, the number of usable attenuation relations is strained.

Since the type of fault affects the occurrence and the effects of the earthquake, it is important on which type of fault the earthquake will occur. Basic fault types and related focal parameters are given in Table 3 .

Based on the focal parameters at the study region fault line Main Marmara Fault (MMF), fault types and the effect of the possible earthquake are modeled. The focal parameters of the MMF are determined from three different studies of the region (Sato et al., 2004; Ansal et al., 2009; Pulido et al., 2004). All three studies show that the focal mechanism (b)

\begin{tabular}{lrrrcr}
\hline Criteria & FT & DS & SC & LP & FM \\
\hline FT & 1 & 0.17 & 0.21 & 0.2 & 0.7 \\
DS & 5.99 & 1 & 1.7 & 1.96 & 3.32 \\
SC & 4.82 & 0.59 & 1 & 1.28 & 1.85 \\
LP & 5.12 & 0.51 & 0.78 & 1 & 2.27 \\
FM & 1.42 & 0.3 & 0.54 & 0.44 & 1 \\
\hline$\lambda \max =5.1$ & $\mathrm{CI}=0.01$ & $\mathrm{CR}=0.01<0.1$ \\
\hline
\end{tabular}

Table 3. Fault classification by focal parameters.

\begin{tabular}{lll}
\hline Fault type & Dip angle $\left(\delta^{\circ}\right)$ & Rake angle $\left(\lambda^{\circ}\right)$ \\
\hline Normal & $40<\delta<70$ & negative \\
Thrust & $10<\delta<40$ & positive \\
Strike-Slip & $\delta=90$ & $0=$ sinistral $/ 180=$ dextral \\
Oblique-Slip & $0<\delta<90$ & $\begin{array}{l}\text { negative }=\text { normal oblique/positive } \\
=\text { reverse oblique }\end{array}$ \\
& &
\end{tabular}

show differences in various locations. The coordinates and the determined focal parameters are ingested into GIS model to visualize the MMF as a line feature in Fig. 2. The ingested focal parameters with the segment and point locations are given in Table 4.

The effect of the fault is calculated and classified by using the fault type effect model of Boore and Atkinson (2007). Boore and Atkinson (2007) developed one of the most current and comprehensive attenuation relations that can be used for the study region. It is a part of the Next Generation Attenuation models project of Pacific Earthquake Engineering Research Center. The main advantage of this model with respect to others is that it includes parameters for each applicable fault type in modeling the earthquake strong motion. This attenuation relation is also used to create a hazard map and to compare with the results of this study.

\subsection{Building the model}

The spatial GIS model is generated by using the ModelBuilder application of ArcGIS software package. The calculated vector weights are attained for each of the five criteria by using spatial analyst tool's weighted sum toolbox after the appropriate classification of all five criteria. The model in Fig. 3 is named the Weighted Earthquake Sum and consists of creation, calculation, classification, and summation of all related criteria.

The maps for the field topography, soil classification, and liquefaction potential are basic inputs. The source to site distance and fault/focal mechanism maps are created based 


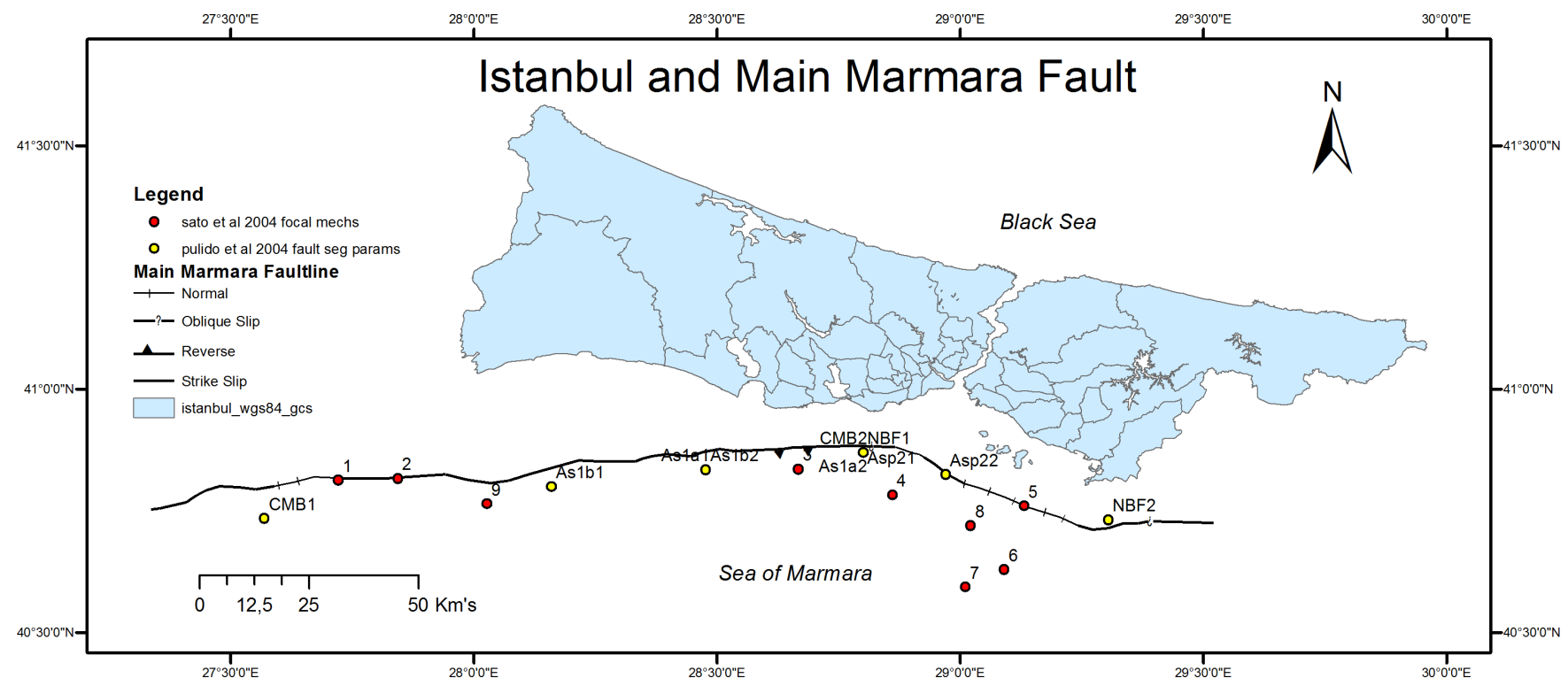

Fig. 2. Main marmara fault line and the focal parameter locations.

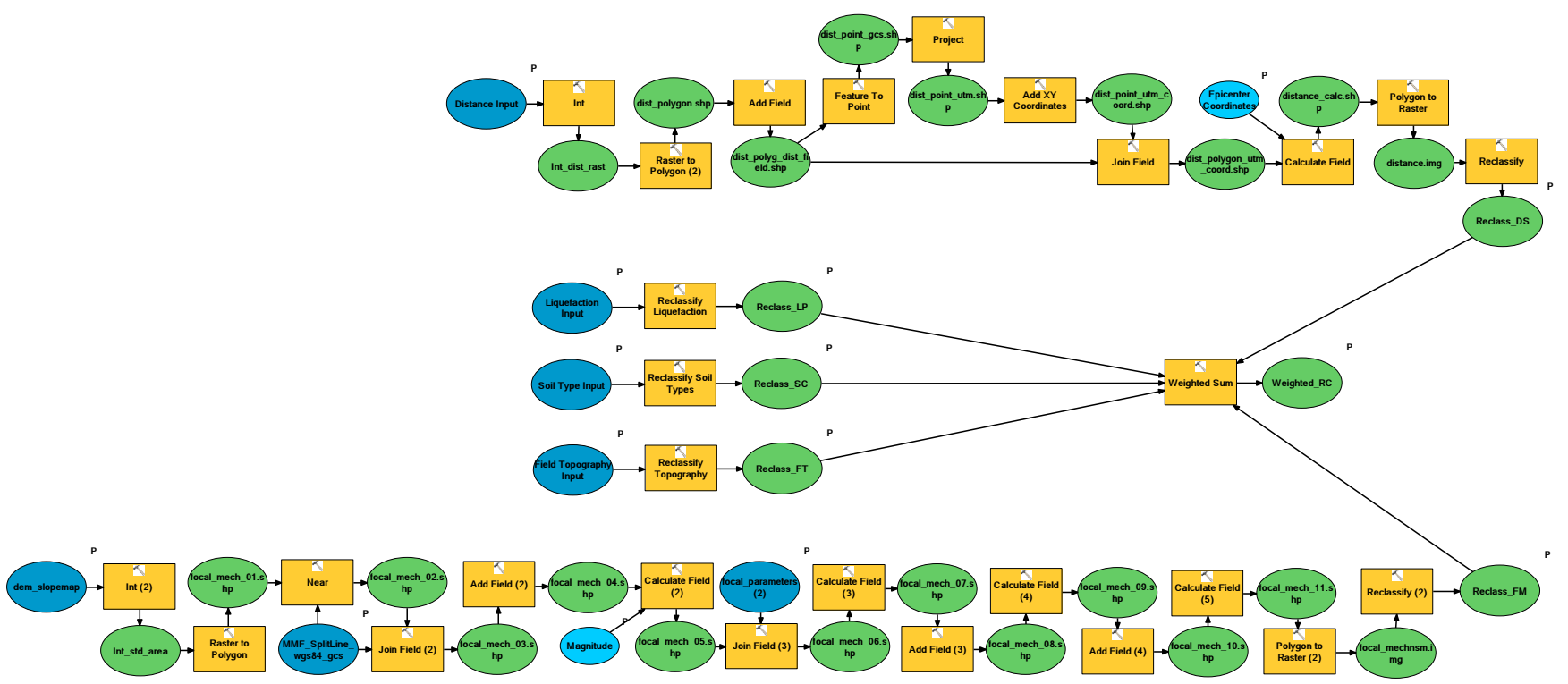

Fig. 3. Weighted Earthquake Sum model chart from the modelbuilder.

on a simple raster map of the study region as mentioned above. At the end of the weighted sum process, a constant parameter is generated to normalize the 1 to 4 classifications and the resulting map for the study is given in Fig. 4. The coordinate system of both inputs and outputs are selected per the World Geodetic System 1984 (WGS84) Geographic Coordinate System (GCS) to minimize the deformation of the projections to distance and area calculations with the spatial data. Another advantage of the model is the ability to combine the maps of the model with the real-time Global Positioning System (GPS) data. Since the GPS coordinates are also in the WGS84 GCS system, there will be no loss of time in disaster management activities to project and operate both data.

\section{Results and comparisons}

The resulting hazard map of our study region is also compared with the Next Generation Attenuation (NGA) model of Boore and Atkinson (2007). The aim of the NGA project is "to develop a new suit of predictive relationships of earthquake ground motion that merge views of experienced attenuation model developers with current research results 
Table 4. Focal parameters of MMF (Sato et al., 2004; Pulido et al., 2004; Ansal et al., 2009).

\begin{tabular}{|c|c|c|c|c|c|c|}
\hline \multicolumn{7}{|c|}{ Pulido (2004) } \\
\hline FID & Segment & Long & Lat & Strike & Dip & Rake \\
\hline 1 & CMB1 & 27.570 & 40.735 & 81.5 & 90 & 180 \\
\hline 2 & CMB2 & 28.800 & 40.870 & 81.5 & 90 & 180 \\
\hline 3 & NBF1 & 28.800 & 40.870 & 110 & 90 & -135 \\
\hline 4 & NBF2 & 29.305 & 40.732 & 110 & 90 & -135 \\
\hline 5 & As1a1 & 28.477 & 40.835 & 81.5 & 90 & 180 \\
\hline 6 & As1a2 & 28.800 & 40.870 & 81.5 & 90 & 180 \\
\hline 7 & As 1b1 & 28.160 & 40.800 & 81.5 & 90 & 180 \\
\hline 8 & As $1 b 2$ & 28.477 & 40.835 & 81.5 & 90 & 180 \\
\hline 9 & Asp21 & 28.800 & 40.870 & 110 & 90 & -135 \\
\hline 10 & Asp22 & 28.970 & 40.825 & 110 & 90 & -135 \\
\hline \multicolumn{7}{|c|}{ Sato (2004) } \\
\hline FID & Depth & Long & Lat & Strike & Dip & Rake \\
\hline 1 & 10.1 & 27.7213 & 40.8132 & 0 & 80 & -10 \\
\hline 2 & 11.2 & 27.8441 & 40.8169 & 70 & 90 & -180 \\
\hline 3 & 7.1 & 28.6669 & 40.8362 & 280 & 90 & 170 \\
\hline 4 & 10.6 & 28.8606 & 40.7832 & 120 & 50 & -100 \\
\hline 5 & 9.6 & 29.1313 & 40.7606 & 0 & 60 & -30 \\
\hline 6 & 6.5 & 29.0901 & 40.6297 & 240 & 50 & -120 \\
\hline 7 & 9.3 & 29.0109 & 40.5939 & 190 & 65 & -40 \\
\hline 8 & 5.3 & 29.0215 & 40.7201 & 120 & 40 & -65 \\
\hline 9 & 5.4 & 28.0273 & 40.7642 & 70 & 90 & -180 \\
\hline \multicolumn{7}{|c|}{ Ansal (2009) } \\
\hline FID & Segment & Long & Lat & Strike & Dip & Rake \\
\hline 1 & $\mathrm{CMBe}$ & 28.8700 & 40.8900 & 81.5 & 90 & 180 \\
\hline 2 & $\mathrm{CMBw}$ & 27.5900 & 40.8000 & 81.5 & 90 & 180 \\
\hline
\end{tabular}

from earth science and engineering communities and satisfies the needs of current and emerging practice in earthquake engineering" (Chiou and Youngs, 2006).

Stafford (2008) also prefers to use the Boore and Atkinson (2007) model for comparisons since the NGA model of Boore and Atkinson (2007) uses the Joyner-Boore distance measure and includes the smallest number of independent variables. This model is consequently a logical choice for making comparisons (Stafford et al., 2008). The hazard map of Boore and Atkinson is created by using the HAZTURK software. Scenario earthquake analysis within the HAZTURK computes ground shaking hazard for a deterministic point source. The scenario earthquake analysis allows users to combine various attenuation relationships or use single ones to produce hazard outputs that specify what outputs it is capable of producing (Karaman et al., 2008a). In hazard map creation, the effect of topography is included, where amplification factors are derived from the terrain profile in Istanbul. Site modification factors are developed for the region based on the detailed soil classification maps that are available for the study area. The resulting hazard map is represented in Fig. 5.

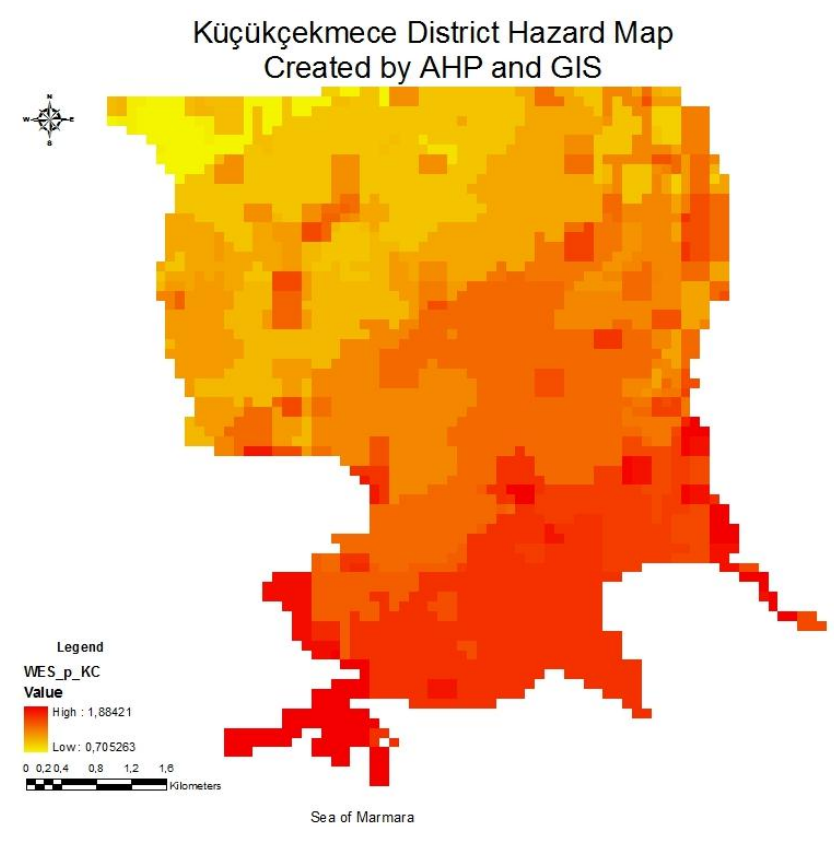

Fig. 4. Hazard map created by AHP and GIS.

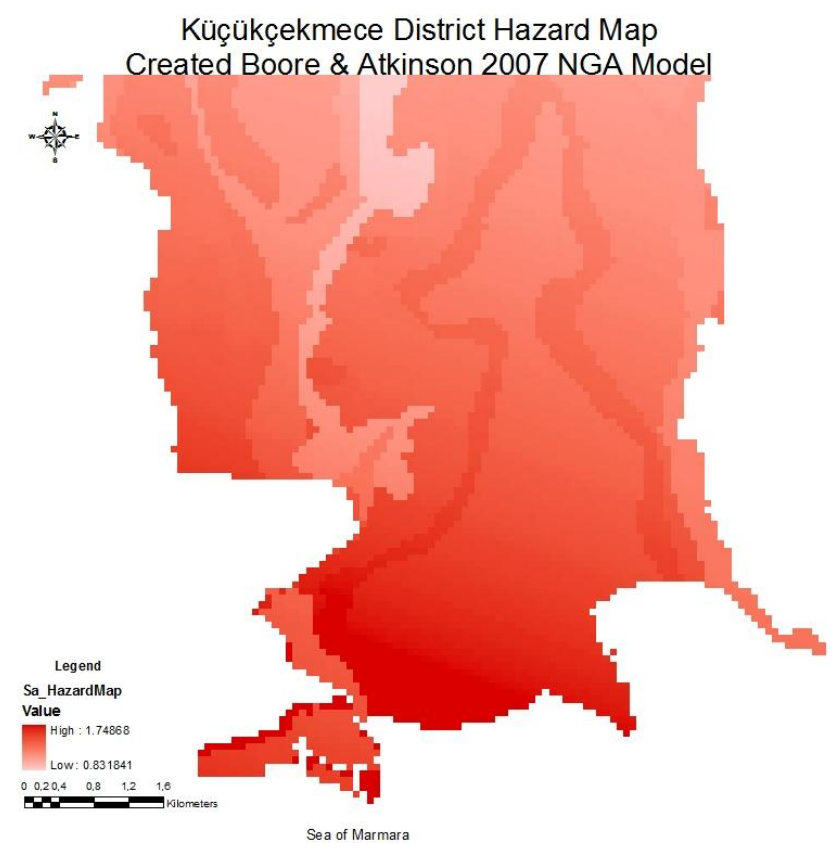

Fig. 5. Hazard map created by Boore and Atkinson (2007) attenuation relation.

Another important comparison related the completed work is how different disciplines evaluate the criteria. This comparison provides a way to see which earthquake criterion is the most or least important one with respect to different disciplines. According to the disciplines of the respondents, the arithmetic mean of the weights/priorities for the criteria and the consistency ratios of the disciplines' respondents are 
Table 5. Aritmetic Means of Respondents with respect to their disciplines.

\begin{tabular}{lrrrr}
\hline \multirow{2}{*}{ Criteria } & \multicolumn{3}{c}{ Aritmetic means of the weights/priorities } \\
\cline { 2 - 5 } & $\begin{array}{r}\text { Civil } \\
\text { Engineers }\end{array}$ & $\begin{array}{r}\text { Geomatics } \\
\text { Engineers }\end{array}$ & $\begin{array}{r}\text { Geophysics } \\
\text { Engineers }\end{array}$ & $\begin{array}{r}\text { Geology } \\
\text { Engineers }\end{array}$ \\
\hline FT (field topography) & $0.07(\% 7)$ & $0.05(\% 5)$ & $0.05(\% 5)$ & $0.05(\% 5)$ \\
DS (source to site distance) & $0.27(\% 27)$ & $0.46(\% 46)$ & $0.35(\% 35)$ & $0.24(\% 24)$ \\
SC (soil classification) & $0.25(\% 25)$ & $0.17(\% 17)$ & $0.33(\% 33)$ & $0.25(\% 25)$ \\
LP (liquefaction potential) & $0.36(\% 36)$ & $0.17(\% 17)$ & $0.18(\% 18)$ & $0.22(\% 22)$ \\
FM (fault/focal mechanism) & $0.05(\% 5)$ & $0.15(\% 15)$ & $0.09(\% 9)$ & $0.24(\% 24)$ \\
Consistency Ratio's & 0.090 & 0.056 & 0.043 & 0.090 \\
\hline
\end{tabular}

given in Table 5. According to the comparison, it is obvious that the source to site distance (DS) criterion is placed as one of top two for every disciplines evaluation, while the field topography (FT) criterion finds itself at last place in the evaluation of all disciplines. For the civil engineers the most important criterion is liquefaction potential (LP), while both geomatics and geophysics engineers select the distance to fault line as the most effective criterion. However, geologists choose the soil classification (SC) as the most important criterion for the earthquake hazard map creation.

\section{Discussions and conclusions}

As can be seen from Figs. 4 and 5, the resulting hazard maps of the region with respect to MCDM and attenuation relations mostly match each other. It can also be recognized from the literature that the variability of the hazard maps, which are created by using different attenuation relations, can also be different from each other.

The comparisons for the related hazard maps provide following values with respect to estimated percentage of buildings, population amount and areas of classified zones. While the fourth class of the hazard map that has been created by the developed model includes 3.65 percent of the buildings of the region, the hazard map created by the use of attenuation relation includes 1.01 percent and the second class has 71.88 percent of the buildings for the developed model, while 76.55 percent were constituted by the attenuation relation. The first class has the best match, while the developed model's hazard map includes 19.35 percent; the attenuation relation generated hazard map includes 19.99 percent of the buildings for the region. If the number of affected population is taken into consideration for comparison of the two hazard maps, the numbers that arise with respect to hazard classification from one to four are $41111,301588,71037$, and 10486 for the developed model and 40 785, 302459,53885 , and 27093 , respectively for the hazard map of attenuation relation. Another comparison can be made with respect to occupied areas of the hazard classes from one to four in the study region. The developed model's hazard map covers
$11606 \mathrm{~km}^{2}, 23903 \mathrm{~km}^{2}, 1150 \mathrm{~km}^{2}$, and $1072 \mathrm{~km}^{2}$ of areas for the classes from one to four, respectively. Supporting these coverage values, the hazard map of attenuation relation covers $11.42 \mathrm{~km}^{2}, 24.08 \mathrm{~km}^{2}, 1.18 \mathrm{~km}^{2}$, and $1.08 \mathrm{~km}^{2}$ of areas for the classes from one to four, respectively. These comparisons illustrate that the generated model has shown a good compatibility with the attenuation relation results.

However, our aim in this study is not to find a method to replace the attenuation relations but to find a way to create high resolution hazard maps more rapidly and with the cooperate opinions of the experts.

The attenuation relations only reflect the opinions, data and analysis results of the scientist/s who develop the relation. However, the AHP takes various opinions and approaches into account, computes a geometric mean of all of those different points of view, and generates a concensus of them by creating a group decision. By this way, more comprehensive results can be obtained in EHM generation.

It is also important to increase the number and the variability of the respondents, which are not enough yet to broaden the opinions. The study will continue different scenarios and different regions to control for the compatibility.

By using the proposed method, the processing time for the creation of an EHM with $100 \mathrm{~m} \times 100 \mathrm{~m}$ resolution took approximately $75 \mathrm{~min}$ for a region of $37.51 \mathrm{~km}^{2}$ areas, while the processing time for the creation of the EHM by using the NGA attenuation relation represented in Fig. 5 with the same area count and resolution the processing time took approximately $225 \mathrm{~min}$. This difference in processing time shows that the proposed model is almost 3 times faster than using a high level attenuation relation. However, the resulting units for the proposed model have not yet been verified to be used for earthquake engineering purposes. That is why, for now, the proposed model is only advised to be used in disaster management and spatial risk analysis purposes.

Edited by: M. E. Contadakis

Reviewed by: E. Tari and another anonymous referee 


\section{References}

Ambraseys, N. N.: The prediction of earthquake peak ground acceleration in europe, Earthq. Eng. Struct. D, 24, 467-490, 1995.

Ambraseys, N. N. and Bommer, J. J.: The attenuation of ground accelerations in europe, Earthq. Eng. Struct. D, 20, 1179-1202, 1991.

Ansal, A., Akinci, A., Cultrera, G., Erdik, M., Pessina, V., Tonuk, G., and Ameri, G.: Loss estimation in istanbul based on deterministic earthquake scenarios of the marmara sea region (turkey), Soil Dyn. Earthq. Eng., 29, 699-709, doi:10.1016/j.soildyn.2008.07.006, 2009.

Arcgis resource center: available at: http://help.arcgis.com/en/ arcgisdesktop/10.0/help/index.html\#/Classifying_numerical_ fields_for_graduated_symbology/00s50000001r000000/, last access: 5 May 2011, 2011.

Boore, D. M.: Equations for estimating horizontal response spectra and peak acceleration from western north american earthquakes: A summary of recent work (vol 68, pg 128, 1997), Seismol. Res. Lett., 68, 128-153, 1997.

Boore, D. M. and Atkinson, G. M.: Boore-atkinson nga ground motion relations for the geometric mean horizontal component of peak and spectral ground motion parameters, Pacific Earthquake Engineering Research CenterPEER 2007/01, 242 pp., 2007.

Carver, S. J.: Integrating multicriteria evaluation with geographical information-systems, Int. J. Geogr. Inf. Syst., 5, 321-339, 1991.

CEN: Eurocode 8: Design of structures for earthquake resistance - part 5: Foundations, retaining structures and geotechnical aspects, Comité Européen de Normalisation, 2, 48 pp., 2004.

Chiou, B. S.-J. and Youngs, R. R.: Chiou and youngs peer-nga empirical ground motion model for the average horizontal component of peak acceleration and pseudo-spectral acceleration for spectral periods of interim report for usgs review (revised editorially July 10, 2006), PEER Center, 219 pp., 2006.

Douglas, J.: Ground motion estimation equations 1964-2003: Reissue of esee report no. 01-1: A comprehensive worldwide summary of strong-motion attenuation relationships for peak ground acceleration and spectral ordinates (1969 to 2000) with corrections and additions, Imperial College London, London, Research Report 04-001-SM, 2004.

Elnashai, A. S., Di Sarno, L., and Wiley InterScience (Online service): Fundamentals of earthquake engineering, Wiley, Chichester, UK, 2008.

Erden, T. and Coskun, M. Z.: Multi-criteria site selection for fire services: the interaction with analytic hierarchy process and geographic information systems, Nat. Hazards Earth Syst. Sci., 10, 2127-2134, doi:10.5194/nhess-10-2127-2010, 2010.

Golden, B. L., Harker, P. T., Alexander, J. M., and Wasil, E. A.: The analytic hierarchy process : Applications and studies, SpringerVerlag, New York, Berlin, vi, 265 pp., 1989.

Jankowski, P.: Integrating geographical information-systems and multiple criteria decision-making methods, Int. J. Geogr. Inf. Syst., 9, 251-273, 1995.

Karaman, H.: Comparison of the istanbul earthquake loss assessment studies, TIEMS 16th Annual Conference, Istanbul, 2009.

Karaman, H., Sahin, M., and Elnashai, A. S.: Earthquake loss assessment features of maeviz-istanbul (hazturk), J. Earthq. Eng., 12, 175-186, doi:10.1080/13632460802014006, 2008a.

Karaman, H., Sahin, M., Elnashai, A. S., and Pineda, O.: Loss assessment study for the zeytinburnu district of istanbul us- ing maeviz-istanbul (hazturk), J. Earthq. Eng., 12, 187-198, doi:10.1080/13632460802014030, 2008b.

Lay, T. and Wallace, T. C.: Modern global seismology, International geophysics series v. 58, Academic Press, San Diego, xii, 521 pp., 1995.

Lee, W. H. K.: International Association of Seismology and Physics of the Earth's Interior, Committee on Education., and International Association for Earthquake Engineering, International handbook of earthquake and engineering seismology, International geophysics series v. 81, Academic Press, Amsterdam, Boston, 2 v., xx, 1945 pp., 2002.

Luna, R. and Frost, J. D.: Spatial liquefaction analysis system, J. Comput. Civil. Eng., 12, 48-56, 1998.

Malczewski, J.: Gis and multicriteria decision analysis, J. Wiley \& Sons, New York, xv, 392 pp., 1999.

National Earthquake Hazards Reduction Program (US), United States. Federal Emergency Management Agency., and Geological Survey (US): 2003 nehrp recommended provisions for seismic regulations for new buildings and other structures and accompanying commentary and maps, 2003 Edn., US Dept. of Homeland Security, Federal Emergency Management Agency, USGS, Washington, DC, 2004.

Parsons, T.: Recalculated probability of $\mathrm{m}=7$ earthquakes beneath the sea of marmara, Turkey, North, 109, 1-21, doi:10.1029/2003jb002667, 2004.

Parsons, T., Toda, S., Stein, R. S., Barka, A., and Dieterich, J. H.: Heightened odds of large earthquakes near istanbul: An interaction-based probability calculation, Science, 288, 661-665, 2000.

Pulido, N., Ojeda, A., Atakan, K., and Kubo, T.: Strong ground motion estimation in the sea of marmara region (turkey) based on a scenario earthquake, Tectonophysics, 391, 357-374, doi:10.1016/j.tecto.2004.07.023, 2004.

Saaty, T. L.: The analytic hierarchy process : Planning, setting priorities, resource allocation, McGraw-Hill International Book Co., New York, London, xiii, 287 pp., 1980.

Sato, T., Kasahara, J., Taymaz, T., Ito, M., Kamimura, A., Hayakawa, T., and Tan, O.: A study of microearthquake seismicity and focal mechanisms within the sea of marmara (nw turkey) using ocean bottom seismometers (obss), Tectonophysics, 391, 303-314, doi:10.1016/j.tecto.2004.07.018, 2004.

Schoppmeyer, J.: Die Wahrnehmung von Rastern und die Abstufung von Tonwertskalen in der Kartographie, Hohen Landwirtschaftlichen Fakultät der Rheinischen, Friedrich-WilhelmsUniversität zu Bonn, 98 pp., 1978.

Stafford, P. J., Strasser, F. O., and Bommer, J. J.: An evaluation of the applicability of the nga models to ground-motion prediction in the euro-mediterranean region, B Earthq. Eng., 6, 149-177, doi:10.1007/s10518-007-9053-2, 2008.

Stein, S. and Wysession, M.: An introduction to seismology, earthquakes, and earth structure, Blackwell Pub., Malden, MA, x, 498 pp., 2003.

Toprak, S. and Holzer, T. L.: Liquefaction potential index: Field assessment, J. Geotech. Geoenviron., 129, 315-322, doi:10.1061/(Asce)1090-0241(2003)129:4(315), 2003.

Vaidya, O. S. and Kumar, S.: Analytic hierarchy process: An overview of applications, Euro. J. Operational Res., 169, 1-29, 2006. 